
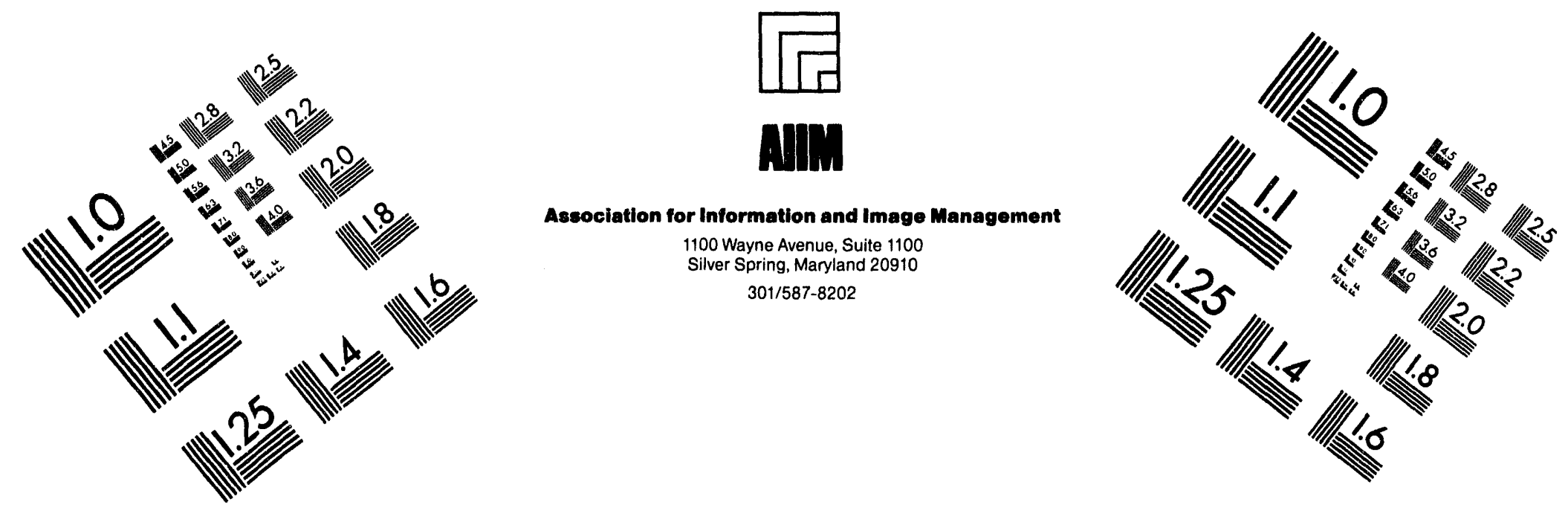

\title{
Centimeter
}

$\begin{array}{llllllllllllllll}1 & 2 & 3 & 4 & 5 & 6 & 7 & 8 & 9 & 10 & 11 & 12 & 13 & 14 & 15 & \mathrm{~mm}\end{array}$ Lши

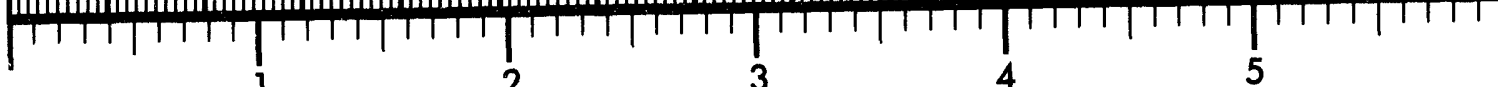
Inches
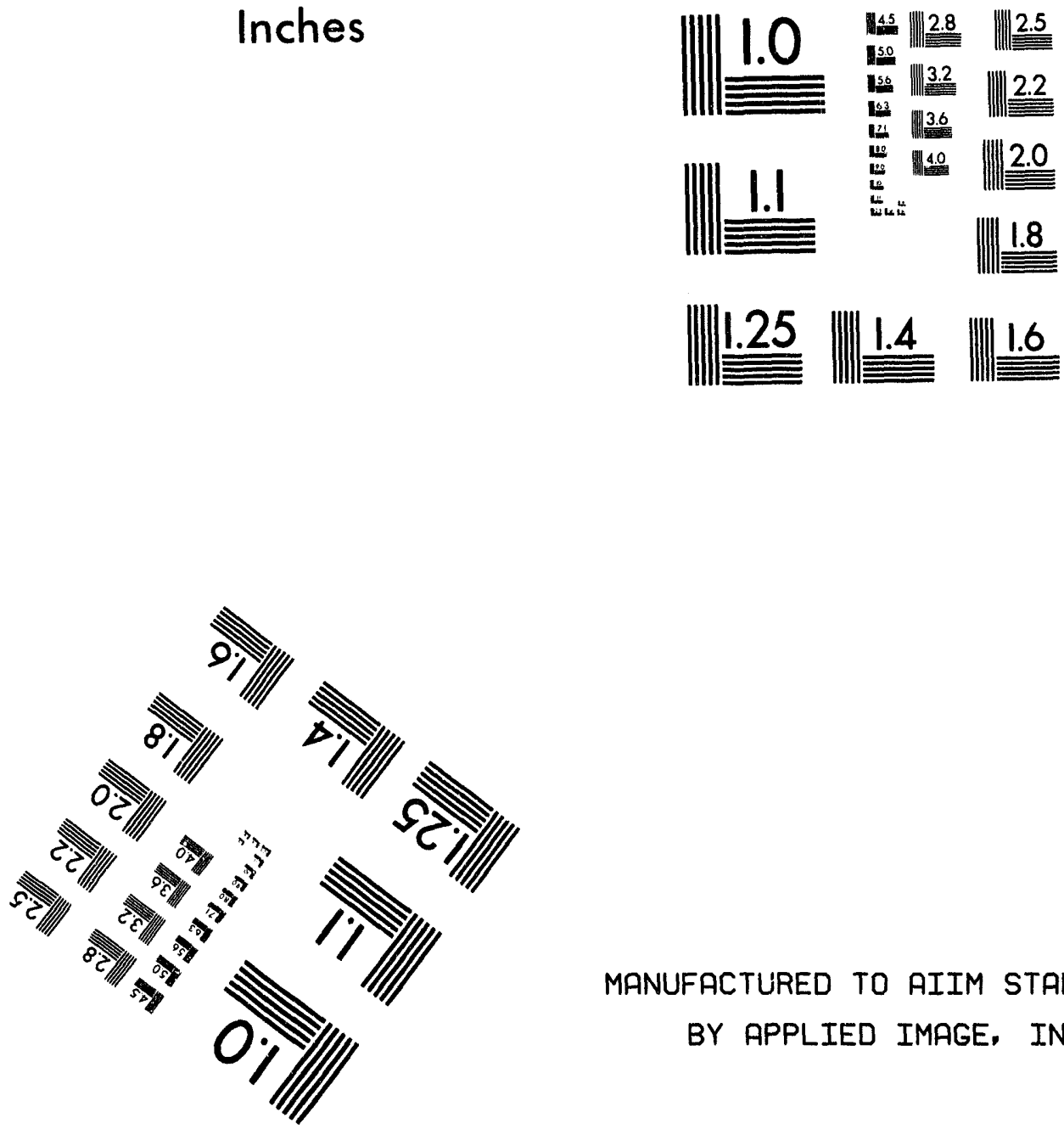

MANUFACTURED TO AIIM STANDARDS BY APPLIED IMAGE, INC.

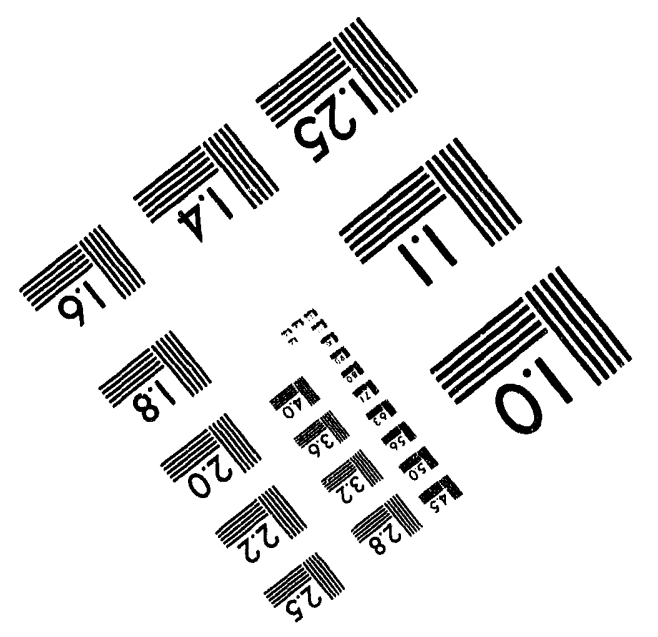




\section{ICRF HEATING OF TFTR DEUTERIUM SUPERSHOT PLASMAS IN THE 3HE MINORITY REGIME ${ }^{+}$}

G. TAYLOR, J.R. WILSON, R.C. GOLDFINGER **, J.C. HOSEA, D.J. HOFFMAN**, R. MAJESKI, C.K. PHILLIPS, D.A. RASMUSSEN**, J.H. ROGERS, G.SCHIILING, J.E. STEVENS, M.G. BELL, R.V. BUDNY, C.E. BUSH**, Z. CHANG*, D. DARROW, D.R. ERNST***, E. FREDRICKSON, G. HAMMETT, K. HIIL, A. JANOS, D. JASSBY, D.W. JOHNSON, L.C. JOHNSON, S.S. MEDLEY, H.K. PARK, J. SCHIVELL, J.D. STRACHAN, E. SYNAKOWSKI, and S. ZWEBEN

Princeton Plasma Physics Laboratory, P.O. Box 451, Princeton, New Jersey 08543, USA

Abstract -- The increased core electron temperature produced by ICRF heating of TFTR, DT neutral-beam-heated supershot plasmas is expected to extend the alpha particle slowing down time and hence enhance the central alpha particle pressure. In preparation for the TFTR D-T operational phase, which is due to start in late 1993, a series of experiments were conducted on TFTR to explore the effect of ICRF heating on the performance and stability of low recycling, deuterium supershot plasmas in the ${ }^{3} \mathrm{He}$ minority heating regime. The coupling of up to 7.4 $\mathrm{MW}$ of $47 \mathrm{MHz}$ ICRF power to full size $(\mathrm{R} \sim 2.62 \mathrm{~m}, \mathrm{a} \sim 0.96 \mathrm{~m}),{ }^{3} \mathrm{He}$ minority, deuterium supershots heated with up to $30 \mathrm{MW}$ of deuterium neutral beam injection has resulted in a significant increase in core electron temperature $\left(\Delta \mathrm{T}_{\mathrm{e}}=3-4 \mathrm{keV}\right)$. Simulations of equivalent $\mathrm{D}-\mathrm{T}$ supershots predict that such ICRF heating should result in approximately a $60 \%$ increase in the alpha particle slowing down time and an enhancement of about $30 \%$ in the central alpha pressure. Future experiments to be conducted at ICRF powers up to $12.5 \mathrm{MW}$ during the upcoming TFTR D-T campaign may result in even greater enhancements in core alpha parameters. This paper presents results from experiments performed at an axial toroidal magnetic field of $\sim 4.8 \mathrm{~T}$, where the mincrity resonance was within $0.1-0.15 \mathrm{~m}$ of the plasma core. Combined ICRF and neutral beam heating powers in these experiments reached TFTR record levels of over $37 \mathrm{MW}$, which allowed an exploration of the power loading limits on the carbon limiter tiles. The plasma current was operated at 1.85 and $2.2 \mathrm{MA}$ and sawtooth suppression was observed at the higher plasma current.

+ This paper is an expanded version of material which originally was a contributed presentation at the 20th EPS Plasma Physics Division Conference, Lisbon, Portugal, July 1993.

*University of Wisconsin, Madison, Wisconsin 53706, USA

**Oak Ridge National Laboratory, Oak Ridge, Tennessee 08731, USA

*** Massachusetts Institute of Technology, Cambridge, Massachusetts 02139, USA

\section{MASTFR}

* Research managed by the Office of Fusion Energy, U.S. Department of Energy, under contract DE-AC05-84OR21400 with Martin Marietta Energy Systems, Inc. 


\section{DISCLAIMER}

This report was prepared as an account of work sponsored by an agency of the United States Government. Neither the United States Government nor any agency thereof, nor any of their employeer, makes any warranty, express or implied, or assumes any legal liability or responsibility for the accuracy, completeness, or usefulness of any information, apparatus, product, or process disclosed, or represents that its use would not infringe privately owned rights. Reference here n to any specific commercial product, process, or service by trade name, trademark, manufacturer, or otherwise does not necessarily constitute or imply its endorsement, recommendatioll, or favoring by the United States Government or any agency thereof. The views and opinions of authors expressed herein do not necessarily state or reflect those of the United States Government or any agency thereof. 
discussed in Sec. III together with results from a D-T plasma simulation. A summary of our conclusions and plans for future work in this plasma regime are presented in Sec. IV.

\section{EXPERIMENT AND RESULTS}

\section{A. DISCHARGE OPTIMIZATION}

Figure 1 shows a poloidal cross-section through the TFTR vacuum vessel and indicates schematically the position of the ICRH antennas and limiter positions. Since the inner limiter has considerably more power handling capability than the outer limiters (SEVIER et al., 1983; PELESSONE et al., 1983) the plasmas in these experiments were run so that the majority of the power flow was to the inboard bumper limiter. However, to simultaneously bring the outer edge of the plasma close to the four ICRH antennas on the outboard side it was necessary to develop a "full bore" (R 2.62m, a $0.96 \mathrm{~m}$ ) supershot plasma. Prior to the 1991-92 TFTR run

period, supershot plasma performance was optimized at $R \sim 2.45 \mathrm{~m}, \mathrm{a} \sim 0.83 \mathrm{~m}$ but with the installation of an upgraded RF limiter in 1991 the supershot performance at the larger major radius was significantly improved (HAWRYLUK et al., 1992).

Supershots are characterized by low edge recycling with all the fueling provided by the beam ions and hence they have a low edge density. However, NBI provides a relatively significant increase in edge density, so that after $100-200 \mathrm{~ms}$ sufficient density had built-up in front of the antennas to allow efficient coupling of ICRH power (MAJESKI et al., 1993). The evolution of the electron density at the last closed flux surface on the outboard side (R $3.6 \mathrm{~m}$ ) from Abel-inverted multi-channel far-infrared interferometer data (MANSFIELD et al., 1987: PARK, 1989) is shown in Fig. 2. The rapid rise in edge density throughout the NBI pulse from 3 to $4 \mathrm{~s}$ (shown lightly shaded in Fig. 2) is particularly challenging for ICRH in this regime since it can result in a factor of 5 to 6 increase in antenna loading imperiance. The start of the ICRH pulse (shown by the darker shading in Fig. 2) was delayed $\sim 200 \mathrm{~ms}$ from the beginning of NBI to allow time for some NBI fueling to occur and the ICRH pulse shape was 
longer interacts with the bottom of the RF limiters. Since this in turn increases the connection length of the outer flux surface it will result in increased power loading at the top of the RF limiters. Furthermore, since the scrape-off length increases as the square root of the connection length some of this power may fall behind the front surface, on the edges of the RF limiters. This effect can increase the power loading significantly since the power falling on the limiter edge is no longer at near-tangential incidence.

\section{SUPERSHOT PLASMA PERFORMANCE WITH ICRH}

Experiments were performed at plasma currents of 1.85 and 2.2 MA. 22-23 MW of NBI was typically employed in the 1.85 MA plasmas and 28-30 MW of NBI was used in the 2.2 MA plasmas. The plasma current and NBI power were chosen to stay well below the empirical TFTR $\beta$ limit, $\beta_{\mathrm{n}}$ was typically $<1.5$ for these discharges. Up to $5.7 \mathrm{MW}$ and $7.4 \mathrm{MW}^{\prime}$ of 47 MHz ICRH power has been coupled into $R \sim 2.62 \mathrm{~m}$, a $\sim 0.96 \mathrm{~m}$ deuterium discharges at a plasma current of 1.85 MA and 2.2 MA, respectively. The plasmas had an axial toroidal magnetic field of $\sim 4.8 \mathrm{~T}$. The Shafranov shift on axis was $0.2-0.25 \mathrm{~m}$ and $0.16-0.2 \mathrm{~m}$ for the 1.8 MA and 2.2 MA plasmas, respectively. The ${ }^{3} \mathrm{He}$ resonance was within $0.1-0.15 \mathrm{~m}$ of the plasma core.

Figure 6 shows a comparison between two plasmas heated with $23 \mathrm{MW}$ of NBI between 3 and 4 seconds. Approximately $60 \%$ of the NBI power was in the direction of the plasma current in both cases. One of these discharges (solid line) had 5.7 MW of ICRH coupled into it between 3.2 and 4 seconds, the other plasma (dashed line) had no ICRH power but both plasmas had a similar size ${ }^{3} \mathrm{He}$ puff at $2.5 \mathrm{~s}$. The central electron temperature measured by electron cyclotron emission (ECE) (STAUFFER et al., 1985) increased by $40 \%$ [Fig.6(b)] and

the diamagnetically measured global stored energy increased by $20 \%$ [Fig.6(c)] with the addition of ICRH. With the application of ICRH the core ion temperature at 3.7 seconds measured by charge exchange recombination spectroscopy (FONCK et al., 1989) increased from 20 to $24 \mathrm{keV}$. The confinement time [Fig.6(f)] and central electron density evolution 
several years ago. This empirical observation remains an unresolved issue and is the subject of an ongoing study (TAYLOR et al., 1993b). The change in central ion temperature [Fig. 7(b)] was of the same order as the $\pm 10 \%$ measurement errors of the charge exchange recombination spectroscopy diagnostic. There was an $\sim 4 \%$ drop in the core electron density (Fig. 7 (c)) and $\sim 10 \%$ drop in density profile peakedness $\left(n_{e}(0) /<n_{e}>\right)$ determined from far-infrared interferometery data. The peakedness degradation was due in part to an increase in edge density, this was correlated with a small increase in $\mathbf{Z}_{\text {eff }}$ measured by visible bremsstrahlung (RAMSEY and TURNER, 1987) from approximately 3.1 to 3.4 with the addition of 5.7 MW of ICRH. The decreased core electron density could result from reduced beam penetration due to the higher edge density and/or $\mathrm{Z}_{\mathrm{eff}} \tau_{\mathrm{E}}$ decreased $5-10 \%$ as the ICRH power was increased [Fig. 7(d)], although this is comparable to the degradation expected for Goldston empirical Lmode scaling (GOLDSTON et al., 1984) it is also of the same order as the uncertainty in the $\tau_{\mathrm{E}}$ measurement. The relatively large scatter in $\tau_{\mathrm{E}}$ with no ICRH is due to variations in wall conditioning. The enhancement over the Goldston empirical L-mode was typically 1.7-2.3 for the 1.85 MA dataset. The measured plasma reactivity [Fig. 7(e)] remained unchanged with the addition of ICRH. Figure 7(f) shows the projected core alpha energy slowing down time calculated for D-T equivalent plasmas, with the same central density and temperature measured during the D-D experiments. A 60\% enhancement in the core alpha particle energy slowing down time was calculated for equivalent D-T plasmas at the highest ICRH powers.

Operation at 2.2 MA was attempted at higher NBI power ( 28-30 MW) and higher ICRH power (up to 7.4 MW). At these higher input powers, plasma performance was relatively poor and unreliable as has already been indicated in the previous section on power handling limits. Global energy confinement times were $15-20 \%$ lower in the 2.2 MA plasmas compared to the 1.85 MA discharges. the enhancement over the Goldston empirical L-mode scaling was only 1.2-1.7 for the 2.2 MA plasmas. Figure 8 provides an overview of the general features of these discharges; the evolution of major plasma parameters for two 2.2 MA plasmas is shown. Discharges that could be directly compared with and without ICRF were difficult to obtain due to variations in plasma conditioning. The two shots of Fig. 8 are generally similar and have the 
by an ECE Grating polychromator (CAVALLO et al., 1988). Measurements of MeV ion loss (ZWEBEN et al., 1990) were also made for these discharges. Escaping MeV ions were measured by detectors at $90^{\circ}, 60^{\circ}$ and $45^{\circ}$ below the outer midplane just outside the limiter radius. The results are shown in Fig.11, where the time at which the ICRH power first steps up is indicated by the vertical dashed line. Although the evolution of the D-D neutron rates for these two plasmas are very similar [Fig.11(b)] the fast ion loss for all three detector locations is considerably enhanced for the plasma with ICRH (solid line) and in particular the signal at the $45^{\circ}$ detector during ICRH is approximately five times that at the $90^{\circ}$ detector [Fig.11(e)]. These observations are qualitatively similar to earlier $\mathrm{MeV}$ ion loss measurements during ${ }^{3} \mathrm{He}$ minority ICRH experiments (ZWEBEN et al., 1992). The time evolution of the signal at all three detectors was examined for evidence of a $10 \mathrm{kHz}$ modulation coincident with the $\mathrm{m}=1$, $n=1$ MHD mode seen on the ECE signal, but none was seen. It would appear therefore that the enhancement in fast ion losses is not due predominantly to the presence of the MHD mode. The enhancement in the fast ion loss at the $90^{\circ}$ detector for the shot with ICRH occurs coincident with the turn-on of the ICRH consistent with the first-orbit loss of $\mathrm{D}-{ }^{3} \mathrm{He}$ fusion product alpha particles, however the enhancement appears to be delayed by 50-100 ms at the $45^{\circ}$ detector, consistent with either ICRH-induced loss of previously confined D-D or D- ${ }^{3} \mathrm{He}$ fusion products, or direct ICRH tail ion losses. Figure 12 shows the dependence of the measured $\mathrm{MeV}$ ion loss on the coupled ICRH power for the plasmas shown in Fig. 7. The signal at the $90^{\circ}$ detector rises relatively little with increasing ICRH power, but the signal at the $45^{\circ}$ detector increases rapidly above $2-3 \mathrm{MW}$. The $45^{\circ}$ detector signal with $6 \mathrm{MW}$ of ICRH is about an order of magnitude greater than the D-D fusion product signal seen with NBI alone and is probably only due to $<1 \%$ of the ICRH tail ion population being lost to the walls. For the same ICRH power scan D-D neutron collimator measurements (JOHNSON, 1992) indicate no apparent broadening of the neutron emissivity profile with increasing ICRH power, consistent with relatively little RF-induced beam ion spreading. 
0.8-1MeV with 5.7 MW of ICRH. In the SNAP computer model the ${ }^{3} \mathrm{He}$ is assumed to have a flat radial concentration profile so that its profile shape is similar to the electron density profile, however recent charge exchange recombination spectroscopy data analysis of ${ }^{4} \mathrm{He}$ transport in supershots (SYNAKOWSKI et al., 1993) suggest a more peaked ${ }^{3}$ He concentration profile may exist in these discharges. In some $(\sim 10 \%)$ of shots analyzed by SNAP with a $2 \%{ }^{3} \mathrm{He} / \mathrm{ne}_{\mathrm{e}}$ concentration, there was insufficient measured electron density to satisfy quasi-neutrality in the calculation. This problem was obviated for most of these shots by reducing the ${ }^{3} \mathrm{He} / \mathrm{n}_{\mathrm{e}}$ concentration in the model to $1.5 \%$. This reduced ${ }^{3} \mathrm{He} / \mathrm{n}_{\mathrm{e}}$ concentration had little effect on the calculated stored energy and increased the predicted neutron production rate by only $1-2 \%$. The anisotropy in the diamagnetically measured stored energy as a function of ICRH power is shown in Fig. 14(b). The energy distribution has a residual parallel component due to the beam ion population which is $\sim 600 \mathrm{~kJ}$ without ICRH. As the ICRH power is increased to $\sim 6 \mathrm{MW}$ the parallel anisotropy drops to $\sim 200 \mathrm{~kJ}$. If this behavior is interpreted as being due entirely to the presence of the perpendicular energy in the RF tail then it implies a tail stored energy, which is consistent with the model results. (The uncertainty in the diamagnetic determination of the tail stored energy is typically 50-100 kJ.) Figure 14(c) shows the calculated fraction of RF power to the electrons as a function of applied RF power. At $5.7 \mathrm{MW}$ just under $50 \%$ of the RF power is calculated to go to electron heating. As the ${ }^{3} \mathrm{He}$ tail slows down it increasingly damps on the ion population near the plasma core, this process accounts for a further $\sim 30 \%$ of the power coupled to the plasma at 5.7MW. The code indicates that the remainder of the RF power $(-20 \%)$ is deposited along the fundamental deuterium and carbon resonance layer on the small major radius side of the discharge, with a distribution which moderately peaks where these resonances intersect the shear Alfven mode conversion layer. At lower ICRH powers ( $\leq$ $2 \mathrm{MW}$ ) this damping mechanism is even more significant and the calculated ICRH power fraction to the fundamental deuterium and carbon resonance layer rises to $\sim 60 \%$. Since the region where these layers intersect is comparable to the poloidal resolution limits in the code, there is some concern that large errors in the predicted RF damping may result. Furthermore, the accuracy of the reduced order approximation which forms the basis for the RF model in the 


\section{SUMMARY AND CONCLUSIONS}

Coupling of up to $7.4 \mathrm{MW}$ of ICRH to deuterium supershot plasmas in the ${ }^{3} \mathrm{He}$ minority regime has resulted in significant core electron heating $\left(\Delta \mathrm{T}_{e} \sim 40 \%\right)$. The enhancement in projected core alpha slowing down time for the 1.85 MA ICRH power scan appears linear with increasing ICRH power [Fig.7(f)] up to the ICRH power levels explored so far ( $5.7 \mathrm{MW})$. The projected alpha particle slowing down time was enhanced $\sim 60 \%$ as a result of the increased core electron temperature. A time dependent D-T simulation indicated the need for longer heating pulses $(\sim 1.4 \mathrm{~s})$ than were used in these experiments, this would provide sufficient time for the increased alpha slowing down time to result in enhanced alpha pressure.

It was apparent that the plasma performance was being degraded as the ICRH power was

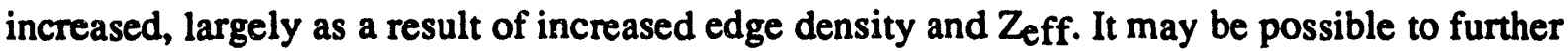
improve performance with additional plasma conditioning. Operation at $2.2 \mathrm{MA}$, at higher total heating powers ( $\sim 37 \mathrm{MW})$ proved problematic; plasma performance was found to be critically dependent on the vertical position of the plasma, however relatively low radiated power fraction $(<15 \%)$ and carbon in-flux was sbtained with up to $35 \mathrm{MW}$ of heating power.

Calculated RF tail energies were found to be consistent with diamagnetic measurements of the residual anisotropy in the energy distribution. RF tail temperatures were calculated to be 0.8-1MeV near the magnetic axis. There was an order of magnitude enhancement in $\mathrm{MeV}$ ion losses with the addition of $5.7 \mathrm{MW}$ of ICRH, although this represents $<1 \%$ of the tail ion population there is some concern that with increased ICRH power fast ion losses could become significant. Although the fraction of RF power calculated to go to the core electron population via ${ }^{3} \mathrm{He}$ tail damping and direct electron heating increased to $\sim 45 \%$ as the RF power was increased there appears to be a saturation in the fraction of RF power to the electrons above $\sim 4 \mathrm{MW}$. Also, modeling indicates that $\sim 20 \%$ of the RF power is deposited on the high field side, along the fundamental deuterium and carbon resonance. Because of concerns regarding 


\section{REFERENCES}

Cavallo A., Cutler R.C. and McCarthy M.P. (1988) Rev. Sci. Instrum. 59, 889.

Fonck R.J. et al. (1989) Phys. Rev. Lett. 63, 520.

Goldston R.J. (1984) Plasma Phys. Controlled Fusion 26, 87.

Hammett G.W. (1986) Ph.D. Thesis, Princeton University.

Hawryluk R.J. et al. (1992) Fusion Tech. 21, 1324.

Johnson D.W., Bretz N., Dimock D., Grek B., Long D., Palladino R. and Tolnas E. (1986)

Rev. Sci. Instrum. 57, 1856.

Johnson L.C. (1992) Rev. Sci. Instrum. 63, 4517.

Majeski R. et al. (1993) in 20th European Physical Society Conf. on Plasma Phys. Controlled

Fusion, Lisbon, 3, 977. (Published by European Physical Society)

Mansfield D.K. et al. (1987) Appl. Opt. 26, 4469.

Murphy J.A., Scott S.D. and Towner H.H., (1992) Princeton Plasma Physics Laboratory Report No. PPPL-TM-393.

Park H.K. (1989) Plasma Phys. Controlled Fusion 31, 2035.

Pelessone D. and Smith P.D. (1983) in the 10th Symposium on Fusion Engineering,

Philadelphia, 1088. (Published by the Institute of Electrical and Electronic Engineers, New York)

Ramsey A.T. and Turner S.L. (1987) Rev. Sci. Instrum. 58, 1211.

Ramsey A.T., Bush C.E., Dylla H.F., Owens D.K., Pitcher C.S. and Ulrickson M.A. (1991) Nucl. Fusion 31, 1811.

Scott, S.D. et al. (1992) in 19th European Physical Society Conf. on Plasma Phys. Controlled Fusion, Innsbruck. (Published by European Physical Society)

Sevier L., Ho M.F., Citrolo J., Bialek J., Weissenburger D. and Zatz I. (1983) in the 10th

Symposium on Fusion Engineering, Philadelphia, 1072. (Published by the Institute of Electrical and Electronic Engineers, New York)

Smithe D.N., Colestock P.L., Kashuba R.J. and Kammash T. (1987) Nucl. Fusion 27, 1319.

Smithe D.N., Phillips C.K., Hammett G.W. and Colestock P.L. (1989) in the 8th Top. Conf. on RF Power in Plasmas, Irvine, 338. (published by the American Institute of Physics, New York)

Stauffer F.J., Boyd D.A, Cutler, R.C. and McCrrthy M.P. (1985) Rev. Sci. Instrum. 56, 925.

Strachan J.D. et al. (1987) Phys. Rev. Lett. 58, 1004.

Synakowski E.J. et al. (1993) Phys. Fluids B 5, 2215. 


\section{FIGURE CAPTIONS}

Fig.1 Schematic diagram showing a poloidal cross-section of the TFTR vacuum vessel.

Fig.2 Evolution of the density at the outer closed flux surface. NBI from 3-4 \& (lighter shading) results in a rapid rise in edge density. The ICRH pulse (darker shading) was delayed from the start of NBI to allow time for density to build in from of the antennas. Also a modest step and ramp were programmed into the start of the ICRH pulse in order to avoid antenna arcs.

Fig.3 Comparison of the evolution of (a) the diamagnetically determined stored energy and (b) neutron reactivity for two similar plasmas heated with $23 \mathrm{MW}$ of NBI. One plasma (thicker line) had a 1 torr.liter/s, $100 \mathrm{~ms}{ }^{3} \mathrm{He}$ puff at $2.5 \mathrm{~s}$, the other plasma had no ${ }^{3} \mathrm{He}$ puff. The helium-3 puff was observed to degrade the stored energy by $\sim 5 \%$ and the neutron reactivity by $\sim 10 \%$.

Fig.4 Radiated power fraction versus total heating power for ${ }^{3} \mathrm{He}$ minority, deuterium supershots at 1.85 and 2.2 MA. Data are at the time of maximum stored energy. For most plasmas the radiated power fraction was $10-15 \%$.

Fig.5 Evolution of plasmas parameters for two plasmas, one centered vertically (thin line) the other positioned $\sim 2 \mathrm{~mm}$ higher (thicker line). Both plasmas had $\sim 36 \mathrm{MW}$ of input heating power, with similar NBI and ICRH power waveforms. The time dependence of (a) the NBI power, (b) the ICRH power, (c) the plasma stored energy, (d) the total radiated power, (e) the $C$-II light and ( $f$ ) the $D_{\alpha}$ light is shown. A significant increase in radiation and a carbon "bloom" is seen for the plasma with the $2 \mathrm{~mm}$ vertical shift. 
Fig.9 Plasma performance during an ICRH power scan of 2.2 MA D-D supershots with 28$30 \mathrm{MW}$ of NBI. Data were obtained at the time of maximum stored energy. (a) the central electron temperature, (b) the neutron production rate, (c) the global energy confinement time, and (d) the projected alpha energy slowing down time for an equivalent $D$-T plasma are plotted versus coupled ICRH power. A linear fit has been made to the data for each plot, the error bars represent typical uncertainties on the data points. Although the observed trends are similar to the 1.85 MA data there is considerable variability in plasma performance. (The open square and circle indicate the shots used for the discharge evolution comparison of Fig. 8.)

Fig.10 The amplitude of Mirnov coil MHD fluctuation data is shown for the two plasmas in Fig. 6. One plasma (solid line) had 5.7 MW of ICRH coupled into it at the time indicated the other (dashed line) had no ICRH. Data are shown for (a) the $m=2$ monitor signal and the amplitude of fluctuations with frequencies in the range (b) 5 $15 \mathrm{kHz}$, (c) $15-25 \mathrm{kHz}$, (d) $25-35 \mathrm{kHz}$, (e) $35-45 \mathrm{kHz}$, (f) $45-55 \mathrm{kHz}$, (g) $55-65$ $\mathrm{kHz}$ and $(\mathrm{h}) 65-75 \mathrm{kHz}$.

Fig.11 Time evolution of the MeV ion losses for the two plasmas shown in Fig.6. (a) The timing of the ICRH and NBI pulses, (b) the D-D fusion rate, (c) the $90^{\circ}$ fast ion loss, (d) the $60^{\circ}$ fast ion loss and (e) the $45^{\circ}$ fast ion loss. The plasma with ICRH coupled is indicated by the solid line. The neutron production rate is similar for the two discharges however the fast ion losses are enhanced significantly in the plasma with ICRH. The $45^{\circ}$ detector signal shows a delayed turn on relative to the initial step in ICRH power (vertical dashed line).

Fig.12 Dependence of the relative fast ion loss versus coupled ICRH power for the 1.85 MA ICRH power scan of Fig.7. 


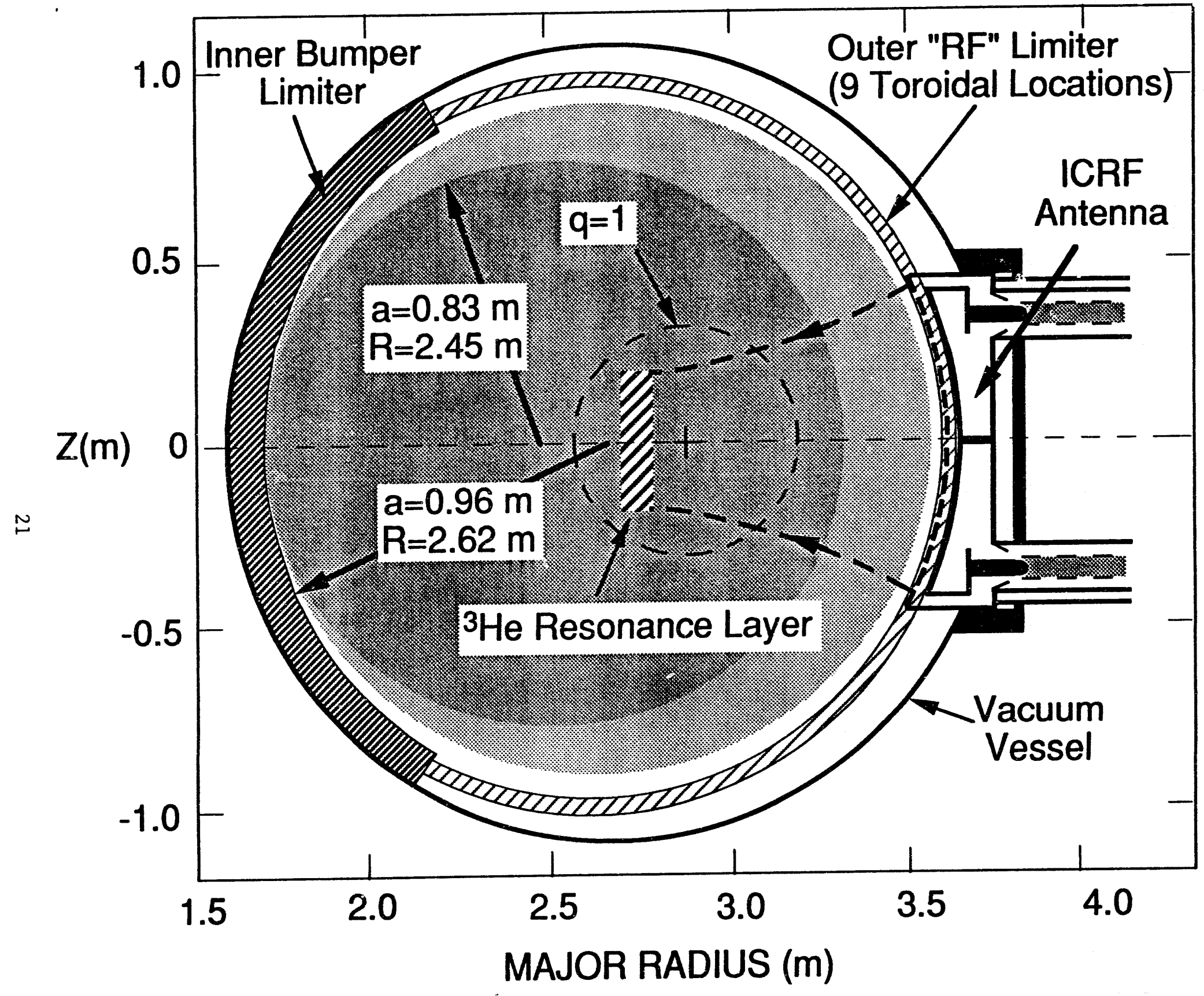




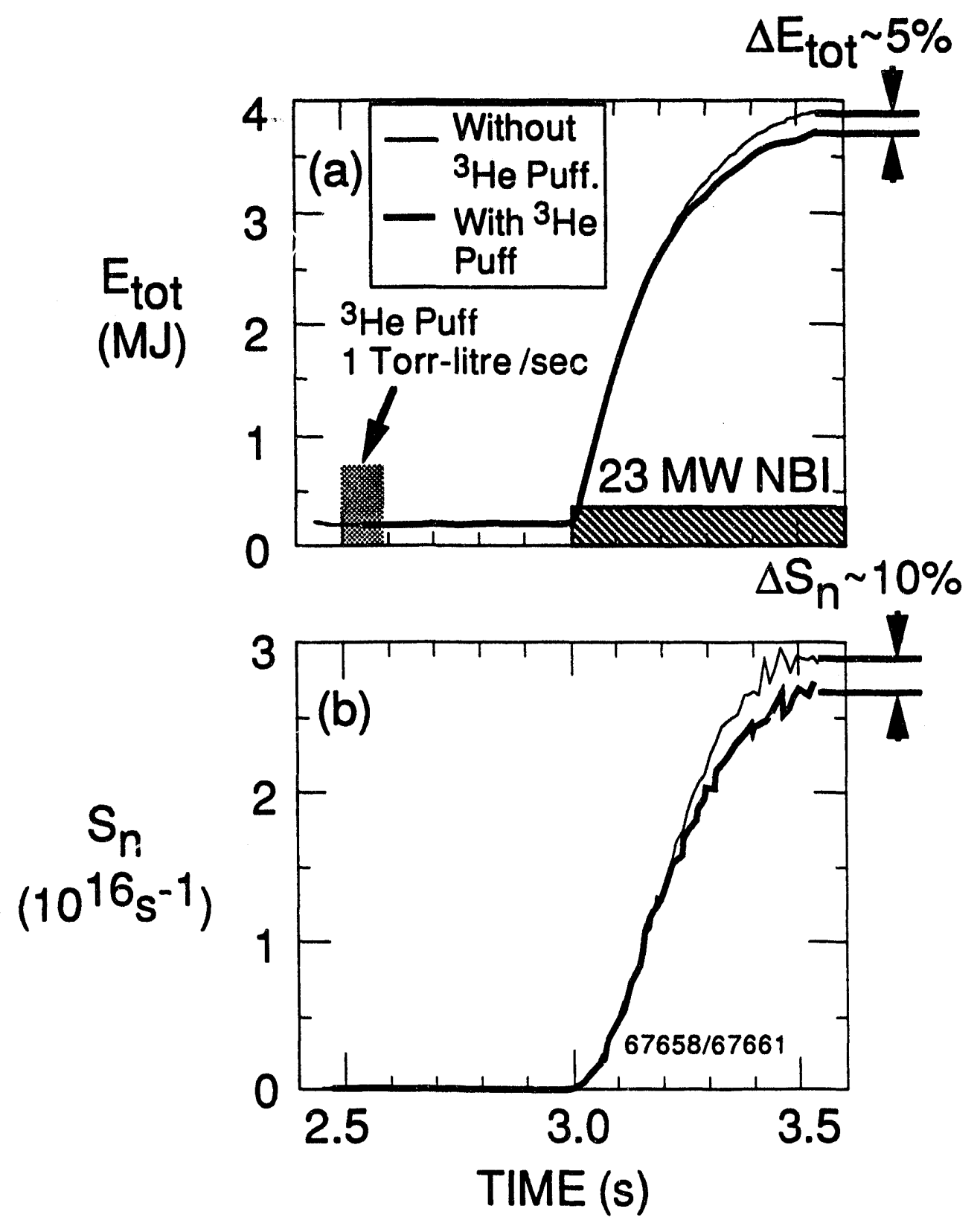

Fig. 3 

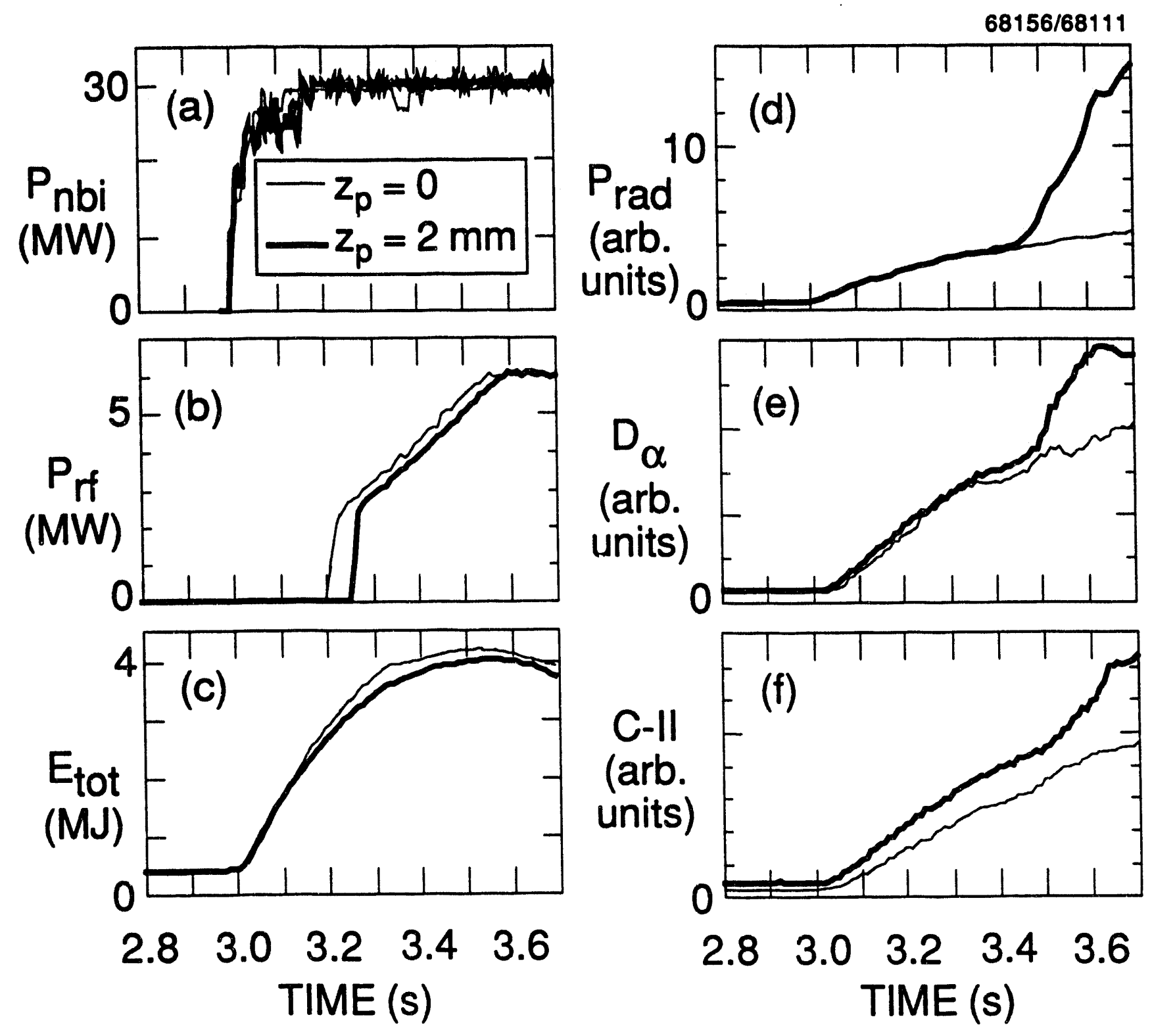

Fig. 5 

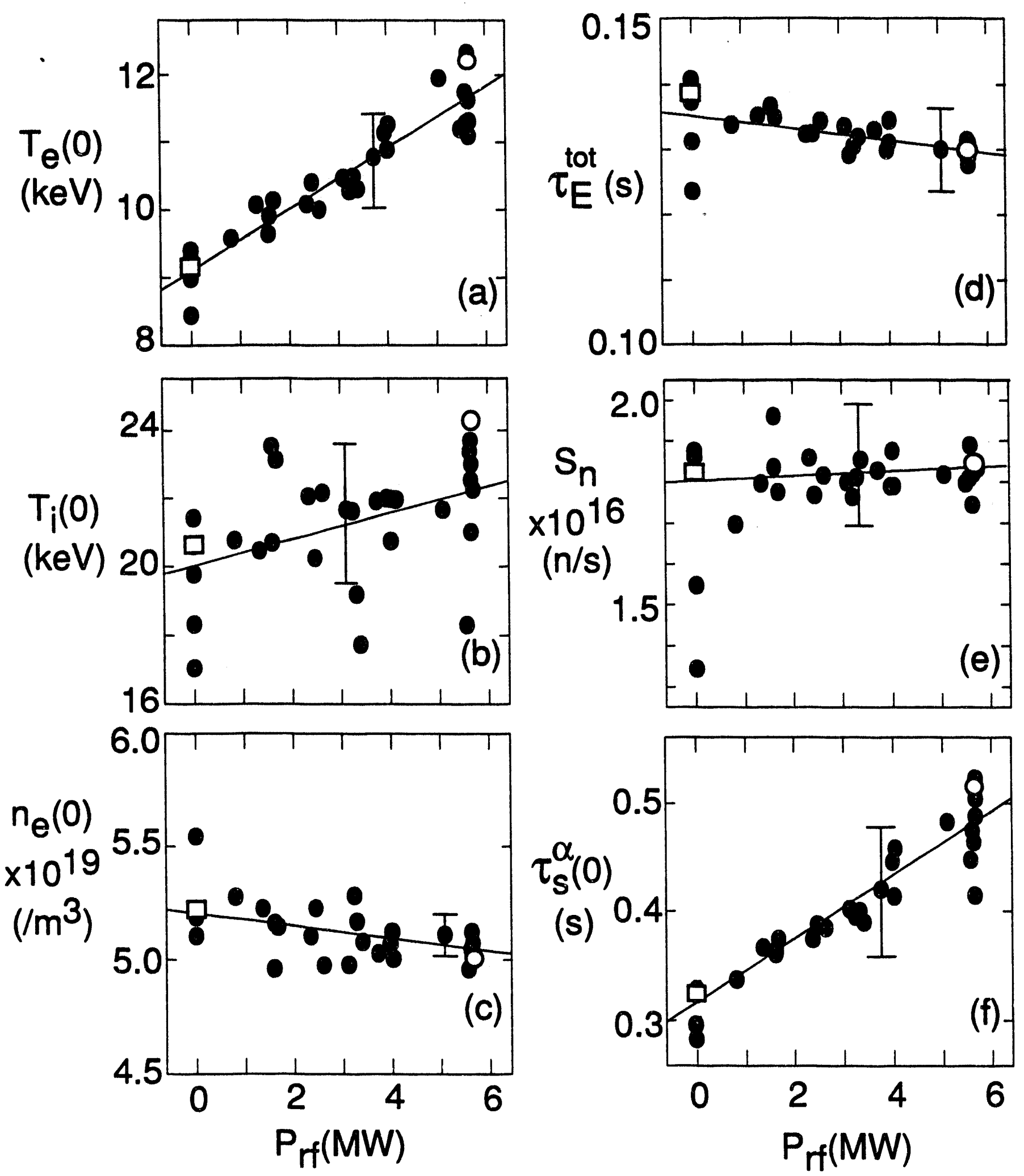

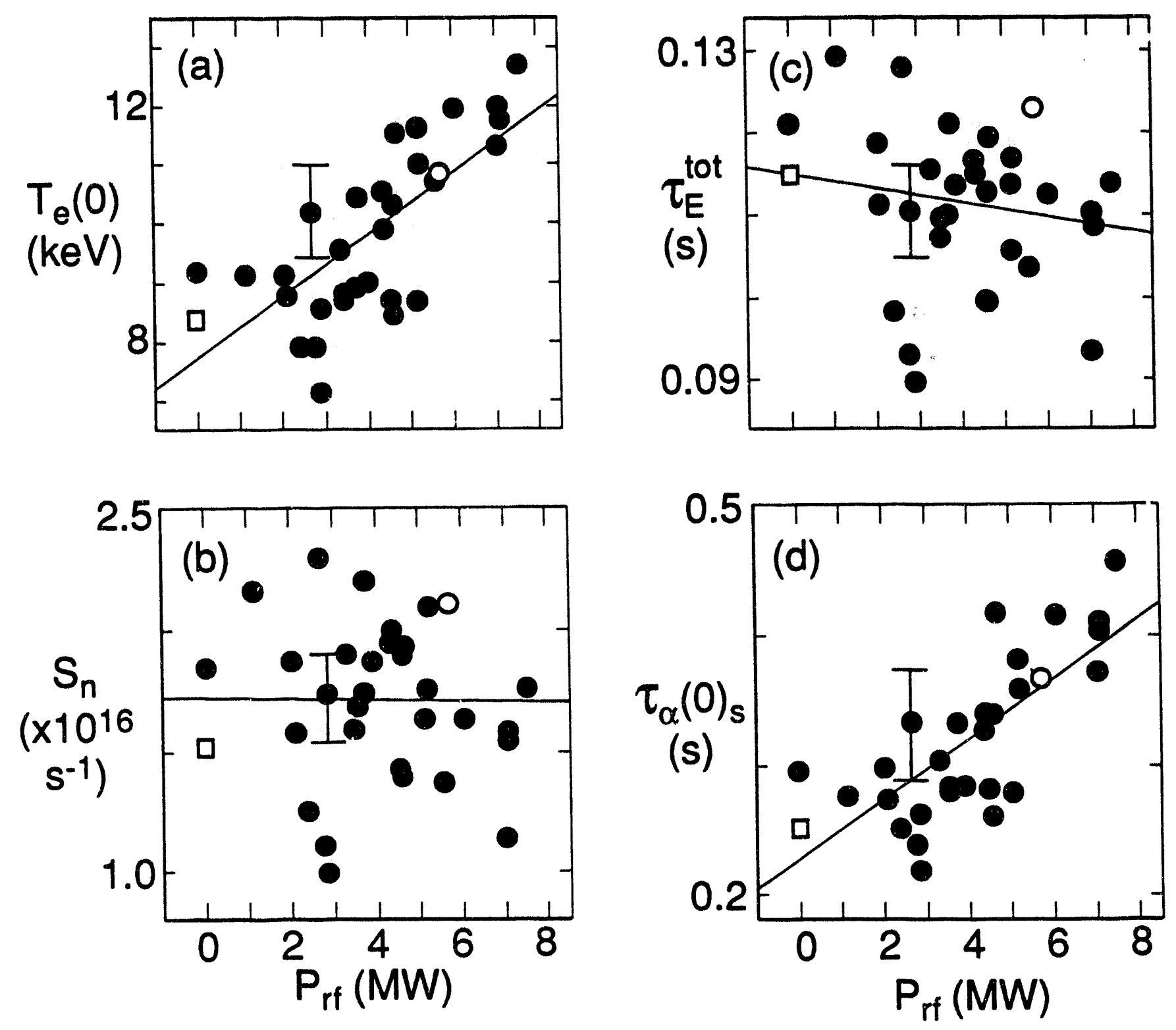

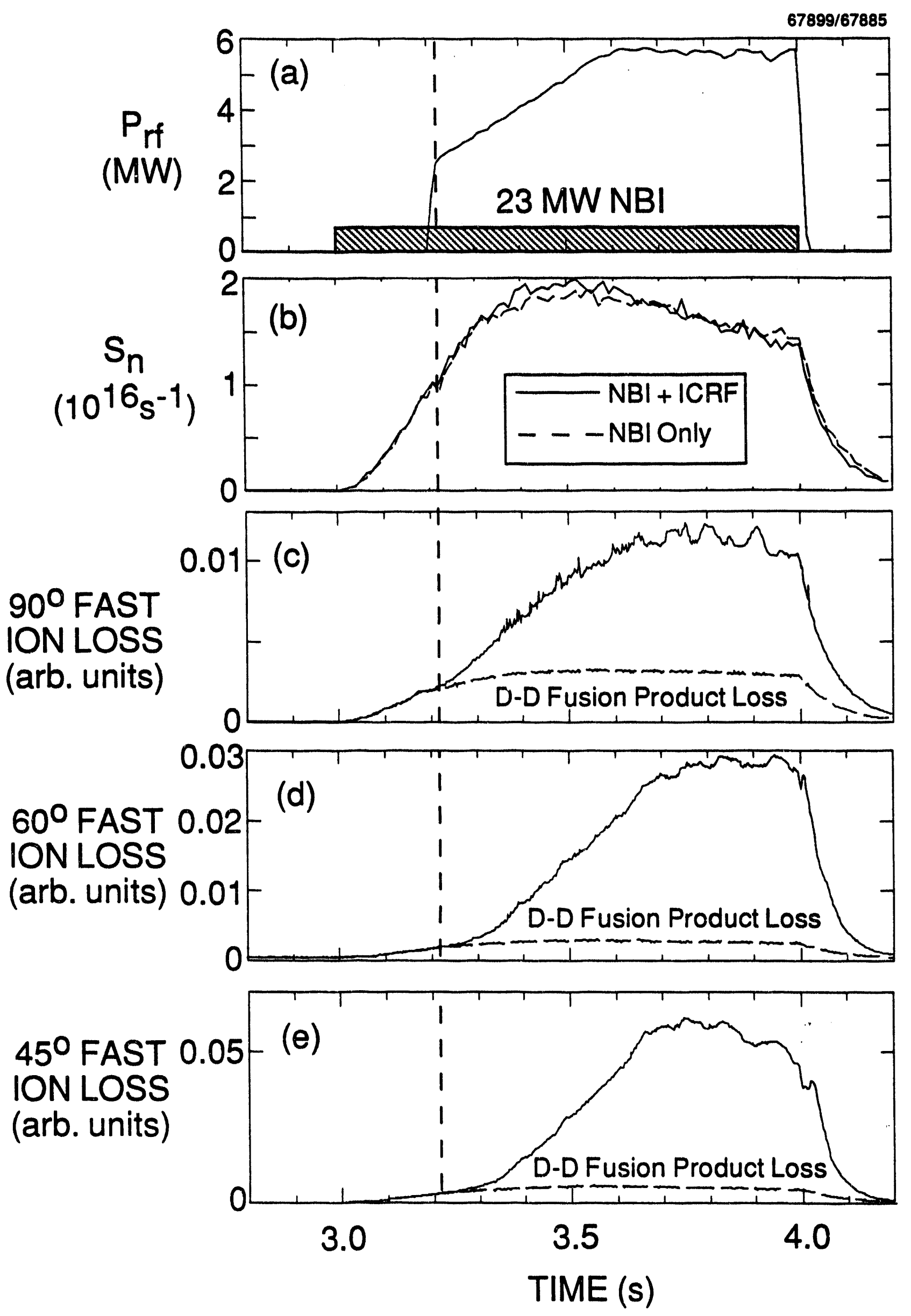

Fig. 11 


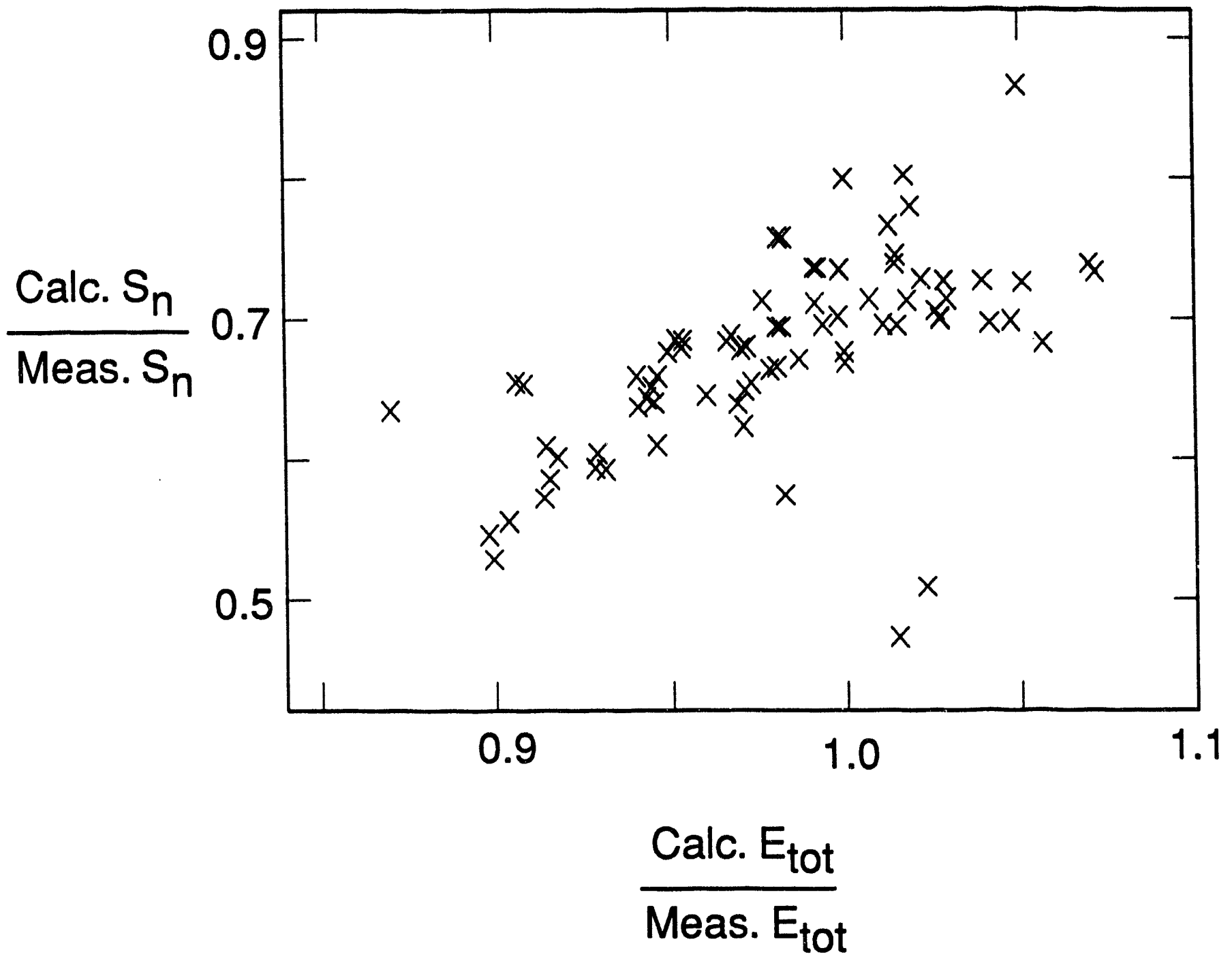

Fig. 13 


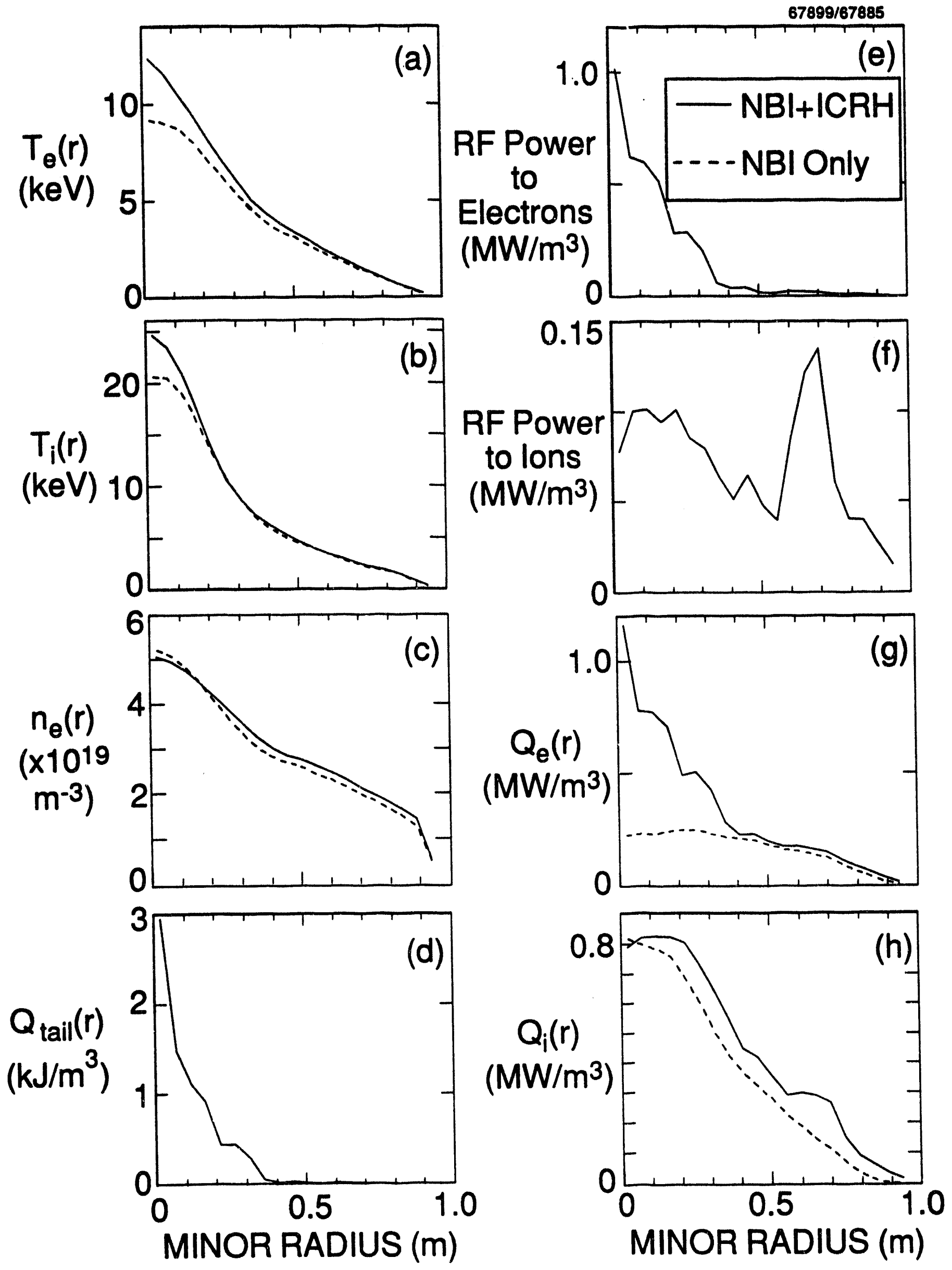


Dr. F. Paoloni, Univ. of Wollongong, AUSTRALIA

Prof. M.H. Brennan, Univ, of Sydney, AUSTRALIA

Plasma Research Lab., Australian Nat. Univ., AUSTRALIA

Prof. I.P. Jones, Flinders Univ, AUSTRALIA

Prof. F. Cap, Inst. for Theoretical Physics, AUSTRIA

Prof. M. Heindler, Institut fur Theoretische Physik, AUSTRIA

Prof. M. Goossens, Astronomisch InstituUt, BELGIUM

Ecole Royale Militaire, Lab. de Phy. Plasmas, BELGIUM

Commission-European, DG. XII-Fusion Prog., BELGIUM

Prof. R. Bouciquó, Rijksuniversiteit Gent, BELGIUM

Dr. P.H. Sakanaka, Instituto Fisica, BPAZIL

Prof. Dr. I.C. Nascimento, Instituto Fisica, Sao Paulo, BRAZIL Instituto Nacional De Pesquisas Espaciais-INPE, BRAZIL

Documents Office, Atomic Energy of Canada Lid., CANADA

Ms. M. Morin, CCFWTokamak do Varennes, CANADA

Dr. M.P. Bachynski, MPB Technologies, Inc., CANADA

Dr. H.M. Skarsgard, Univ. of Saskatchewan, CANADA

Prof. J. Teichmann, Univ. of Montreal, CANADA

Prot. S.R. Sreenivasan, Univ, of Calgary, CANADA

Prof. T.W. Johnston, INRS-Energie, CANADA

Dr. R. Bolton, Centre canadien de fusion magnétique, CANADA

Dr. C.R. James, Univ. of Alberta, CANADA

Dr. P. Lukác, Komenskeho Universzita, CZECHO-SLOVAKIA

The Librarian, Culham Laboratory, ENGLAND

Library, R61, Rutheriord Appleton Laboratory, ENGLAND

Mrs. S.A. Hutchinson, JET Library, ENGLAND

Dr. S.C. Shama, Univ. of South Pacific, FIJI ISLANDS

P. Mahounen, Univ. of Helsinki, FINLAND

Prof. M.N. Bussac, Ecole Polytechnique,. FRANCE

C. Mouttet, Lab. de Physique des Milieux lonisés, FRANCE

J. Radet, CEN/CADARACHE - Bat 506, FRANCE

Prot. E. Economou, Univ. of Crete, GREECE

Ms. C. Rinni, Univ. of loannina, GREECE

Preprint Library, Hungarian Academy of Sa., HUNGARY

Dr. B. DasGupta, Saha Inst. of Nuclear Physics, INDIA

Dr. P. Kaw, inst. for Plasma Research, INDIA

Dr. P: Rosenau, Israel inst. of Technology, ISRAEL

Librarian, Intemational Center for Theo Physics, ITALY

Miss C. De Palo, Associazione EURATOM-ENEA , ITALY

Dr. G. Grosso, Istituto di Fisica del Plasma, ITALY

Prot. G. Rostangni, Istituto Gas Ionizzati Del Cnr, ITALY
Dr. H. Yamato, Toshiba Res a Devel Center, JAPAN

Prof. I. Kawakami, Hiroshima Univ., JAPAN

Prof. K. Nishikawa, Hiroshima Univ., JAPAN

Librarian, Naka Fusion Research Establishment, JAEAI, JAPAN

Director, Japan Atomic Energy Research Inst., JAPAN

Prof. S. Itoh, Kyushu Univ., JAPAN

Research Info. Cr., National Instit. for Fusion Science, JAPAN

Prof. S. Tanaka, Kyoto Univ., JAPAN

Libray, Kyoto Univ., JAPAN

Prot. N. Inove, Univ. of Tokyo, JAPAN

Secretary, Plasma Section, Electrotechnical Lab., JAPAN

S. Mori, Technical Advisor, JAERI, JAPAN

Dr. O. Mitarai, Kumamoto Inst. of Technology, JAPAN

Dr. G.S. Lee, Korea Basic Sci. Crr., KOREA

J. Hyeon-Sook, Korea Atomic Energy Research Inst., KOREA

D.I. Choi, The Korea Adv. Inst. of Sai. \& Tech., KOREA

Prof. B.S. Liley, Univ. of Waikato, NEW ZEALAND

Inst of Physics, Chinese Acad Sci PEOPLE'S REP. OF CHINA

Library, inst. of Plasma Physics, PEOPLE'S REP. OF CHINA

Tsinghua Univ. Library, PEOPLE'S REPUBLIC OF CHINA

Z. Li, S.W. Inst Physics, PEOPLE'S REPUBLIC OF CHINA

Prof. J.A.C. Cabral, Instituto Superior Tecrico, PORTUGAL

Prot. M.A. Hellberg, Univ. of Natal, S. AFRICA

Prof. O.E. Kim, Pohang Inst. of Sci. \& Tech., SO. KOREA

Prof. C.I.E.M.A.T. Fusion Division Library, SPAIN

Dr. L. Stenflo, Univ. of UMEA, SWEDEN

Libray, Royal inst. of Tochnology, SWEDEN

Prot. H. Wilhelmson, Chalmers Univ. of Tech., SWEDEN

Centre Phys. Des Plasmas, Ecole Polytech, SWITZERLAND

Bibliotheok, Inst. Voor Plasma-Fysica, THE NETHERLANDS

Asst. Prot. Dr. S. Cakir, Middle East Tech. Univ., TURKEY

Dr. V.A. Glukhikh,Sci. Res. Inst. Electrophys.I Apparatus, USSR

Dr. D.D. Ayutov, Siberian Branch of Academy of Sci., USSR

Dr. G.A. Eliseev, I.V. Kurchatov Inst., USSR

Librarian, The Ukr.SSR Academy of Sciences, USSR

Dr. LM. Kovrizhnykh, Inst. of General Physics, USSR

Kemforschungsanlage GmbH, Zentrabbibliothek, W. GERMANY

Bibliothek, Inst. Für Plasmatorschung, W. GERMANY

Prol. K. Schindler, Ruhr-Universitát Bochum, W. GERMANY

Dr. F. Wagner, (ASDEX), Max-Planck-Institut, W. GERMANY

Librarian, Max-Planck-Institut, W. GERMANY 

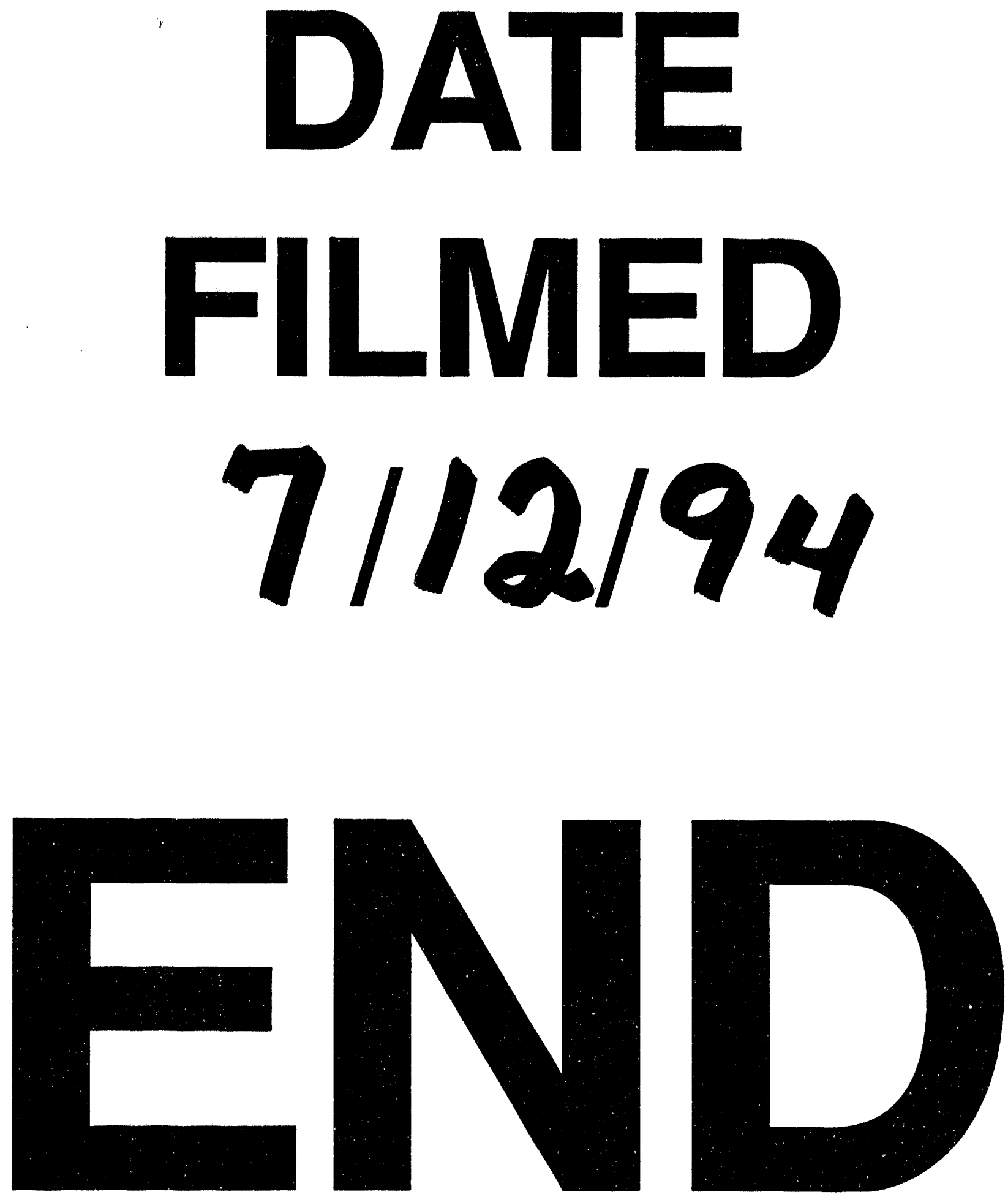

4 
